\title{
RACIONALIDADES NO FAZER ARTÍSTICO: ESTUDANDO A PERSPECTIVA DE UM GRUPO DE TEATRO
}

\author{
THE RATIONALE BEHIND DOING ART: STUDYING THE PERSPECTIVE OF A THEATER GROUP \\ RACIONALIDADES EN EL HACER ARTÍSTICO: ESTUDIANDO LA PERSPECTIVA DE UN GRUPO DE TEATRO
}

\section{RESUMO}

O objetivo deste artigo foi discutir quais tipos de racionalidade orientam a prática artística contemporânea. Tal objetivo surgiu a partir de uma pesquisa realizada no Grupo Galpão, um grupo de teatro belo-horizontino que existe há 28 anos. Conforme se adentrou no lócus de pesquisa, por meio de análise documental, observações de não participantes e entrevistas, a questão da racionalidade emergiu como um tema proeminente para se discutir a produção da arte na contemporaneidade. Por meio de elementos da análise do discurso, eviden- ciaram-se, nas práticas discursivas dos artistas, sentidos do fazer artístico algumas vezes ligados à racionalidade instrumental e à sobrevivência no mercado de bens culturais, e outras vezes ligados à racionalidade substantiva e à prática orientada por ideais éticos ou estéticos. Ao final, entende-se que, apesar das pressões econômicas advindas do contexto da indústria cultural, a arte autêntica é intrinsecamente uma prática transcendente e resguarda momentos de liberdade e de afirmação de valores extracotidianos

PALAVRAS-CHAVE Racionalidade, arte, indústria cultural, produção artística, grupo de teatro.

Mariana Mayumi Pereira de Souza mariana_mayumi@yahoo.com.br

Professora do Curso de Administração do Campus Florestal, Universidade Federal de Viçosa - Florestal - MG, Brasil

Alexandre de Pádua Carrieri alexandre@cepead.face.ufmg.br

Professor do Centro de Pós Graduação e Pesquisas em Administração, Universidade Federal de Minas Gerais -

Belo Horizonte - MG, Brasil

\begin{abstract}
This paper aims at discussing which rationality types may orient contemporary artistic practice. This objective emerged from a research made in Grupo Galpão, a twenty-eight years old theatre group from Belo Horizonte. As we entered into the research locus, by documental analysis, non participant observation and interviews, the rationality issue became a prominent theme to be discussed considering contemporary art production. By means of discourse analysis elements, we could identify in artists' discursive practices meanings about art-making, sometimes related to instrumental rationality and to surviving in the market of cultural goods; and sometimes, on the other hand, were related to substantive rationality and to practices oriented by ethical or esthetical ideals. By the end, despite of economic pressures from the cultural industry context, we understand that authentic art is intrinsically a transcendent practice and keeps moments of freedom and assertion of out-of-the-ordinary life values.

keywords Rationality, arts, cultural industry, artistic production, theatre group.

Resumen El objetivo de este artículo fue discutir cuales tipos de racionalidad orientan la práctica artística contemporánea. Tal objetivo surgió a partir de una investigación realizada en el Grupo Galpão, un grupo de teatro de la ciudad de Belo Horizonte que existe hace 28 años. Según se adentró en el locus de investigación, por medio de análisis documental, observaciones de no participantes y entrevistas, la cuestión de la racionalidad emergió como un tema importante para se discutir la producción de la arte en la contemporaneidad. Por medio de elementos del análisis del discurso, se evidenciaran, en las prácticas discursivas de los artistas, sentidos del hacer artístico algunas veces conectados a la racionalidad instrumental y a la sobrevivencia en el mercado de bienes culturales, y otras veces conectados a la racionalidad substantiva y a la práctica orientada por ideales éticos o estéticos. Al final, se entiende que, a pesar de las presiones económicas resultantes del contexto de la industria cultural, la arte auténtica es intrínsicamente una práctica trascendente y protege momentos de libertad y de de afirmación de valores fuera de lo común. Palabras clave Racionalidad, arte, industria cultural, producción artística, grupo de teatro.
\end{abstract}




\section{INTRODUÇÃO}

O presente artigo tem como objetivo discutir os tipos de racionalidades que orientam o fazer artístico. Tal objetivo surgiu a partir de uma pesquisa realizada no Grupo Galpão, um grupo de teatro que existe há 28 anos em Belo Horizonte (MG). Conforme se adentrou no lócus de pesquisa, a questão da racionalidade emergiu como um tema proeminente para se discutir a produção da arte na contemporaneidade. Por se tratar de um produto cuja natureza é altamente autoral e cujo valor assume sentidos simbólicos, como é o caso do fazer dos artistas contemporâneos, a compreensão do inter-relacionamento das racionalidades na prática - principalmente quando esses artistas se encontram agrupados de forma organizacional - poder gerar contribuições relevantes para estudos no campo das organizações chamadas culturais ou criativas (BENDASSOLLI e outros, 2009; LAMPEL e outros, 2009; GALLEN; BOUDER-PAILLER, 2010).

O interesse pela compreensão do fazer artístico foi estimulado devido às funções sociais diferenciadas que a produção artística de forma geral tem assumido a partir do século XX. Observa-se a crescente utilização de obras de arte como mercadorias oferecidas de forma massificada ao público. A arte, nesse contexto, estaria cada vez mais esvaziada de sentido, perderia sua autonomia em relação ao mundo material e à sua função política emancipadora. Torna-se, dessa forma, impregnada pela racionalidade instrumental do mercado (HORKHEIMER; ADORNO, [1949] 2007). Nota-se, no Brasil e no mundo, a franca expansão do setor cultural, entendido como espaço de criação, consumo e geração de emprego. É notável o crescimento de investimentos financeiros para essa área e o número cada vez maior de pessoas que possuem a arte como ocupação principal (AVELAR, 2008; BENDASSOLLI, WOOD JR; 2010).

Tendo em vista a complexidade do contexto histórico e macrossocial, o sistema social particular estudado, conforme já exposto, foi o Grupo Galpão. O Galpão surgiu a partir da associação de quatro atores que se conheceram em uma oficina de teatro oferecida por dois membros alemães do Teatro Livre de Munique. Dos alemães, foram herdadas as influências do teatro de rua, do trabalho circense e do dramaturgo Bertold Brecht, cuja obra é reconhecida como politizada e contestadora (SOARES, 2002). Atualmente, o Grupo Galpão é composto por treze atores sócios e é um dos grupos de teatro mais atuantes no Brasil, sendo patrocinado por grandes empresas, como a Petrobras. Ao longo de seus quase trinta anos, o grupo produziu dezoito espetáculos, recebeu dezenas de premiações e fundou um espaço cultural o Galpão Cine Horto, que conta com uma estrutura de aproximadamente quarenta funcionários.

Em sua trajetória, o Galpão adquiriu reconhecimento nacional e internacional, tendo se apresentado em todas as regiões do Brasil e em vários países da Europa, América do Norte e América Latina. Um marco na história do grupo foi a realização de uma série de apresentações da montagem de Romeu e Julieta na reinauguração do Shakespeare's Globe Theatre em Londres, no ano 2000. Foi o primeiro grupo brasileiro a se apresentar nesse local (BRANDÃO, 2002). Nesse sentido, tendo em vista a relevância do Galpão no cenário artístico brasileiro e internacional, ele foi selecionado para ser estudado enquanto caso particular, mas que pode ser revelador de insights que gerem novas zonas de sentido para se compreenderem outros grupos de teatro e outras organizações de produção artística de forma geral (REY, 2005).

Ao penetrar na esfera cotidiana do Grupo Galpão, observou-se que a criação artística ocorria quando os espaços de interação permitiam aos sujeitos liberdade para manifestarem abertamente suas ideias, para testar práticas, ou seja, para agir de forma racionalmente substantiva. Tais constatações vão ao encontro da visão da arte enquanto atividade que requer transcendência das condições materiais vividas. Sendo necessário admitir a separação entre as atividades humanas transcendentes e aquelas voltadas simplesmente a questões mundanas, o estudo se orientou ontologicamente segundo a lógica dialética, baseada na filosofia negativa (MARCUSE, 1973). Apesar de se reconhecer a existência de diversas perspectivas a respeito das relações entre arte, cultura e sistema econômico (BENDASSOLLI e outros, 2009) ao se abordar o tema da racionalidade no fazer artístico contemporâneo, optou-se pela perspectiva dos autores da Escola de Frankfurt por entendê-la como mais congruente ao posicionamento ontológico adotado nesta pesquisa.

Entende-se que as práticas cotidianas poderiam estar direcionadas à existência material no mundo ou a atividades que a transcendam. Em momentos de existência, o indivíduo se dedica ao simples cumprimento de papéis sociais e pauta sua conduta em função de sua relação objetiva com o mundo. Em momentos de transcendência, por outro lado, o indivíduo poderia se dedicar à contemplação, à arte, à interação autêntica e ao pensamento crítico. Entende-se que a razão humana opera de forma diferenciada em atividades de existên- 
cia e de transcendência, sendo as primeiras pautadas basicamente pela racionalidade instrumental e as últimas, pela racionalidade substantiva (ARENDT, 2004; MANNHEIM, 1986; RAMOS, 1981). Nesse sentido, para entendimento do fazer artístico nas práticas individuais e coletivas, há de se considerar a inter-relação entre ambas as instâncias, enquanto um processo dinâmico. Tal dinâmica assume nuances mais complexas quando se trata de grupos articulados para a produção artística em um contexto da indústria cultural (RAMOS, 1981; CERTEAU, 1994; HORKHEIMER; ADORNO, 1947; BENDASSOLLI e outros, 2009; DUARTE, 2002; GLYNN, 2000).

Bendassolli e outros (2009) apontam para a necessidade de pesquisas no âmbito das chamadas indústrias culturais e criativas na área de Estudos Organizacionais, focando os processos organizativos internos, a formulação e realização da estratégia, os modelos de gestão e o trabalho de indivíduos e grupos de artistas. Além disso, poderia ser focado o relacionamento entre as dimensões comerciais e artísticas. Estudiosos têm ressaltado recentemente a proeminência de sentidos paradoxais na produção de arte, tais como profissionalismo ou amadorismo, valorização intrínseca ou extrínseca do trabalho, manutenção de valores artísticos ou entretenimento de massa, diferenciação ou inovação na criação das obras, liberdade de criação ou formulação de processos criativOS (BENDASSOLLI; WOOD JR, 2010; LAMPEL e outros, 2009; DEFILLIPPI e outros, 2007) .

O artigo está dividido em cinco partes, inclusive esta introdução, em que foram apresentados os objetivos, as premissas iniciais da pesquisa e as conclusões resumidamente antecipadas. No item a seguir, serão discutidos conceitos sobre racionalidade e a questão da racionalidade na prática artística. Em seguida, são apresentados os procedimentos metodológicos empreendidos na pesquisa empírica que fundamenta este artigo. No quarto item, são expostas as análises. Por último, seguem-se as considerações finais.

\section{RACIONALIDADES}

A discussão sobre a racionalidade humana remete diretamente às premissas tomadas como verdadeiras e que desencadeiam o pensamento lógico. Sob o prisma do pensamento filosófico negativo, a razão humana poderia operar segundo diferentes critérios; basicamente, aqueles relacionados à existência e aqueles relacionados à transcendência (TUGENDHAT, 2002). Ao se tratar do tema da racionalidade, Weber ([1901] 2004) foi pioneiro ao diferenciar quatro tipos de racionalidade: racional referente a fins; racional referente a valores; racional afetivo e racional tradicional. Apesar da diferenciação, o autor coloca que, na ação social, haveria quase sempre uma mistura de racionalidades envolvidas. Mannheim ([1929] 1986) se baseia claramente nas ideias de Weber (2004) ao discorrer sobre a racionalidade substancial e a funcional.

A racionalidade substancial estaria baseada em julgamentos independentes de acontecimentos em determinada situação, que permitiriam uma conduta ética e responsável. Desencadearia um "ato de pensamento que revela percepção inteligente das inter-relações dos acontecimentos de uma determinada situação" (MANNHEIM, 1986, p. 63). Por meio do exercício da razão substancial, o homem transcenderia a condição de um ser puramente natural, relacional e socialmente determinado, pautando sua vida segundo imperativos éticos ou estéticos dessa razão e transformando-se em um ator político (RAMOS, 1981).

A racionalidade funcional diria respeito ao reconhecimento de qualquer conduta, acontecimento ou objeto como sendo apenas meio para se atingir uma meta. Estaria relacionada a uma série de atos que, para atingir o objetivo, coordena os meios mais eficientemente. Cada ato tem um papel funcional na consecução do objetivo final. A série de atos é funcional quando está organizada funcionalmente em relação ao objetivo, e suas consequências são calculadas. A ação racional funcional seria observada tanto em limites de uma organização que opera planos estratégicos de certas autoridades quanto em sociedades solidificadas pela tradição cujas ações individuais têm sentido pela sua função no todo (MANNHEIM, 1986).

Mannheim (1986) expande os conceitos de funcional e de substancial para a esfera da moralidade. Uma disciplina moral seria funcional quando postula padrões de conduta que garantem o funcionamento suave da sociedade. Em contrapartida, a moralidade substancial estaria baseada em valores concretos, arraigados na fé, na ética, na estética ou em outros tipos de sentimento que podem parecer irracionais sob o ponto de vista funcional. Na sociedade moderna, observa-se a tendência a se neutralizar a moralidade substancial, principalmente no espaço público. A influência exacerbada da moralidade funcional impediria as qualificações éticas da vida humana. Os valores humanos tornam-se valores econômicos, acordos tácitos ou explícitos baseados em um cálculo utilitário de consequências. Diante disso, Mannheim (1986) sustenta que seria necessário proteger a vida humana 
contra a expansão crescente da racionalidade funcional, acarretada pela industrialização.

A partir das distinções de Weber (2004) e das definições de Mannheim (1986), Ramos (1981) defende que somente os atos substancialmente racionais é que atestam a capacidade de transcendência do ser humano e sua qualidade de criatura racional. A racionalidade substancial se relaciona à preocupação humana em resguardar a liberdade. Somente por meio dela é que o indivíduo se liberta da integração positiva numa série sistemática de outros atos. Essa integração impede a ação inteligente.

Apropriando-se das perspectivas dos autores citados neste tópico, sustenta-se aqui a visão de que é própria da natureza humana a interação cotidiana baseada em diferentes tipos de racionalidade: a instrumental e a substantiva. Enquanto o instrumental trata de assuntos relativos à existência, o substancial trata de valores transcendentais, arraigados à crença no bom, no belo e no verdadeiro. Esses valores constituem a capacidade do homem de possuir pensamento crítico, de crer em um vir-a-ser, de negar as condições dadas, de transformar o mundo e a si mesmo, enfim de produzir a arte em sua vida. Na sociedade moderna, contudo, restam poucas esferas da vida humana em que a racionalidade substantiva possa operar nas ações e relações dos indivíduos. Vizeu (2005) assinala que os próprios valores das teorias da administração e da organização formal encontram-se baseados na racionalidade instrumental. Dessa forma, a arte no contexto capitalista tardio merece um exame mais minucioso. No tópico a seguir apresentase uma retrospectiva histórica das relações entre a arte e os sistemas sociais, apontando-se os significados e as racionalidades assumidos pela arte ao longo do tempo.

\section{Racionalidade na arte}

A história da arte acompanha a história da humanidade, desde seus primórdios. Pode-se dizer que a necessidade humana de produzir arte está atrelada à necessidade de transcendência, ao próprio processo de "humanização" e ao processo civilizatório, no qual o homem apreende regras que viabilizam e justificam o convívio social. Tais regras se sofisticam até se tornarem complexos sistemas culturais (BENJAMIN, 1994).

Para lançar luz sobre as relações entre arte e sociedade na contemporaneidade, retoma-se inicialmente o período do Renascimento até o século XIX, pois é nessa época que a burguesia ascende ao poder e que ocorrem grandes mudanças nos valores culturais da sociedade europeia. Marcuse ([1937] 2001) explica que a partir da era burguesa a ideia clássica de que alguns nascem des- tinados ao ócio, para pensar e cultuar o belo, e outros nascem para o trabalho é derrubada pela tese da universalidade e validade geral da "cultura". Para ascender ao poder, a burguesia implanta uma nova ética, baseada na racionalidade, na competição e na materialidade. A partir desse processo, a cultura passa a exercer uma dominação historicamente nova, do tipo afirmativo. Ao ser elevada a uma falsa universalidade, a cultura passa a reafirmar a realidade e a negar as contradições sociais existentes.

O fim da época da ascendência burguesa é marcado pelo liberalismo econômico e pelas revoluções industriais. Nesse período, que se estende até o início do século XX, o capitalismo se consolida como modo de produção e os valores culturais burgueses se tornam cada vez mais dominantes. A cultura afirmativa atinge seu ápice e contribui para o isolamento cada vez maior dos indivíduos. Aqueles que sofrem na vida material com sua posição social aprendem a buscar uma felicidade solitária e individualizada (HORKHEIMER; ADORNO, 2007; MARCUSE, 2001).

A transição do capitalismo liberal para o monopolista está fundamentada, basicamente, no desenvolvimento da técnica. O capitalismo, para sobreviver, necessita que a produção cada vez maior seja escoada e alcance as massas, que passam a assumir o duplo papel de proletárias e de consumidoras. A relação entre arte e sociedade nesse contexto se torna diferenciada, pois a cultura não mais assume função afirmativa. Os elementos culturais, como a arte, deixam de compor o reino da felicidade imaterial e transcendental. A cultura se integra ao reino da necessidade e da transitoriedade, passa a fazer parte do plano econômico e a ser reproduzida em escalas industriais. Tornam-se acessíveis às massas a diversão, o lazer e a ideia de que um mundo melhor já pode ser alcançado. A indústria cultural se baseia na noção de que qualquer sensação e qualquer sentimento estão ao alcance do consumidor (MARCUSE, 2001; HORKHEIMER; ADORNO, 2007).

$\mathrm{Na}$ indústria cultural, a arte e a cultura, de forma geral, perderiam sua relação dialética com a civilização, pois se encontrariam entrelaçadas com a vida cotidiana e banal. A obra de arte há de ser contextualizada para levar à transcendência. Somente assim ela remete à sua tradição e se mantém autêntica, idêntica a si mesma. Entretanto, na cultura industrializada, com o avanço das técnicas de reprodutibilidade, a arte perde sua unicidade. Guiada pela necessidade, a arte assume então função contrária à libertação da obra autêntica: ela impede que os homens se libertem do reino da instrumentalidade. O valor de uso da arte é substituído pelo valor de troca; o prazer estético perde espaço para a ideia de "estar em 
dia”. A arte, como mercadoria, se torna fetiche. A produção artística, portanto, se esvaziaria de racionalidade substantiva para se submeter à instrumentalidade (BENJAMIN, 1994; HORKHEIMER; ADORNO, 2007).

O emprego dos chamados "bens culturais" como mercadorias oferecidas de forma massificada ao público é um fenômeno ainda mais verificável nos dias de hoje. Emerge nesse contexto o discurso do "marketing cultural", segundo o qual os artistas devem se vender para empresas patrocinadoras em busca de financiamento para seus projetos. No caso brasileiro, em que os recursos são mais escassos e majoritariamente controlados por agentes privados, estabelece-se uma concorrência entre os próprios artistas para que seus projetos sejam patrocinados em detrimento de outros. Nesse sentido, surge a tensão entre oferecer o que os financiadores querem e manter o espaço criativo e autônomo do artista (AVELAR, 2008; OLIVEIRA e outros, 2007).

No processo de expansão do setor cultural, Avelar (2008) chama a atenção para a procura por profissionalização e formalização da gestão cultural. Segundo Matta e Souza (2009, p. 30), o atual quadro da produção artística envolve a formação de sistemas particulares de carreiras, que seriam mais parecidas com redes de trabalhadores "criativos", que oferecem o suporte às "culturas de produção". Com o aumento da complexidade desse setor, surgem novos papéis e atores, como o agenciador de talentos, as redes de provedores de recursos financeiros, o diretor, e os produtores independentes. Para Bendassolli e outros (2009), esses profissionais trabalham normalmente em equipes polivalentes, devido à natureza das atividades, cujo processo produtivo exige a coordenação de diferentes competências, especialidades e recursos.

A partir desse contexto, Bendassolli e outros (2009) apontam para a necessidade de pesquisas no âmbito das chamadas "indústrias culturais e criativas" na área de Estudos Organizacionais, focando os processos organizativos internos, a formulação e realização da estratégia, os modelos de gestão e o trabalho de indivíduos e grupos de artistas. Além disso, poderia ser focado o relacionamento entre as dimensões comerciais e artísticas. De acordo com a concepção dos estudos de indústrias culturais, na qual se insere este estudo, observa-se que as organizações culturais não são pautadas unicamente pela racionalidade instrumental, pois as concepções estéticas e artísticas têm forte influência sobre as escolhas e os direcionamentos de recursos. Entretanto, a necessidade de sobrevivência econômica leva essas organizações a situações conflitantes e ambíguas, nas quais a instrumentalidade, a funcionalidade e a racionalização típicas do mercado se chocam com instâncias artísticas
(BENDASSOLLI e outros, 2009; GLYNN, 2000; BENDASSOLLI; WOOD JR, 2010; LAMPEL e outros, 2009).

O debate em torno do papel da cultura e da arte na sociedade capitalista tardia é longo e encontra-se longe de conclusões definitivas. Para esta pesquisa, acredita-se que a arte poderia assumir funções afirmativas ou negativas perante o sistema, sendo pautada por diferentes racionalidades. Isso irá depender do posicionamento político de quem é detentor dos meios de produção, da forma como a arte é levada ao público e da capacidade do público de compreendê-la (BENJAMIN, 1994). Sobre a capacidade de compreensão do público, ressalta-se o risco de se negligenciar demasiadamente o senso crítico dos indivíduos, generalizandoos como uma massa de trabalhadores ingênua e acrítica. Acredita-se que haveria possibilidades de brechas na tendência ao totalitarismo cultural. Apesar da ênfase dada à massificação da cultura, os autores de Frankfurt reconhecem a possibilidade de os indivíduos resistirem ao domínio ideológico (BENJAMIN, 2007; ADORNO, 2007). Benjamin (2007) demonstra grande interesse pelas práticas cotidianas dos indivíduos. Ao mesmo tempo que o autor enxerga a fantasmagoria na multidão e nas mercadorias, reconhece que os sujeitos ainda seriam capazes da rememoração e da experiência, ou seja, de transceder e buscar o mundo da liberdade.

Considerando a capacidade de resistência subjetiva, recorre-se aos conceitos de Certeau (1994), como vias epistemológicas de investigação. Para esse autor, os indivíduos se apropriam dos elementos simbólicos constituintes da estrutura social de forma ativa, criando bricolagens. Dessa maneira, aqueles que se encontram em condição de dominação são capazes de manter certas práticas de resistência, as táticas. A subjetividade dos indivíduos, portanto, jamais seria apreendida em sua totalidade. Sempre haveria espaço para a contestação e a reconstrução de significados simbólicos, mesmo que isso não represente uma mudança social estrutural e imediata.

Dessa forma, os indivíduos, em meio à influência da indústria cultural, ainda poderiam ter seu espaço de criação, de crítica e de exercício da racionalidade substantiva. Tal espaço seria assegurado tanto pelas práticas de resistência individuais (táticas) quanto por práticas coletivas em agrupamentos sociais em que predomina a racionalidade substantiva. Esse seria $O$ caso, por exemplo, de grupos de artistas que buscam subverter a racionalidade instrumental do mercado por meio de esforços conjuntos em uma a convivência comunitária e com menor prescrição de normas (RAMOS, 1981). 
A partir do referencial teórico exposto, evidencia-se que a arte, apesar de subjugada ao sistema capitalista, ainda poderia constituir espaços para a transcendência humana. Essa transcendência seria resguardada pela busca ética ou estética - a busca do bom ou do belo com base em valores extrassociais (TUGENDHAT, 2002). Sob essa perspectiva, a arte seria inerente a vivências transcendentes. Nesse sentido, considerou-se imprescindível fomentar a discussão sobre as racionalidades que estariam por trás das práticas cotidianas dos artistas.

\section{METODOLOGIA}

Tendo em vista a coerência com as posições teóricoepistemológicas traçadas anteriormente, a metodologia de pesquisa seguiu um caminho qualitativo. A pesquisa foi construída sobre uma base ontológica subjetivista, cuja operacionalização empírica foi realizada pela estratégia do estudo de caso no Grupo Galpão (REY, 2005). Segundo Yin (2001), o estudo de caso é adequado quando a questão de pesquisa visa desvendar o "como" ou o "por que", quando não há controle sobre eventos comportamentais por parte do pesquisador ou quando são focalizados acontecimentos contemporâneos. Portanto, o estudo de caso é interessante para a compreensão das relações entre a racionalidade e a produção de arte, pois entende-se que tais relações são demasiadamente complexas e exigem um estudo aprofundado de determinada realidade, envolvendo o conjunto de múltiplos métodos de coleta e tratamento de dados. Um único caso é considerado válido, pois, quando estudado a fundo, a realidade se revela específica e particular, permitindo gerar novas zonas de sentido ou espaços de inteligibilidade capazes de abrir caminhos para o aprofundamento em um campo de construção teórica (REY, 2005). Para o estudo, foram coletados dados secundários, observações e entrevistas. Os dados e observações preliminares foram coletados entre fevereiro e julho de 2008. As entrevistas e observações de ensaios, apresentações e reuniões foram realizadas entre maio e outubro de 2009. No intervalo entre os dois períodos, a pesquisadora acompanhou as atividades do Grupo Galpão periodicamente e de forma assistemática.

Os dados secundários captaram informações históricas preliminares sobre o Grupo Galpão, discursos institucionais e inalcançáveis por meio das entrevistas. Esses dados foram buscados em documentos, jornais e revistas, principalmente no Centro de Pesquisa e Memória do Teatro (CPMT), acervo mantido pelo próprio Grupo Galpão. As observações geraram notas de campo, nas quais a pesquisadora imputou, além de eventos e discursos específicos, as suas próprias reflexões, sobre as quais se apoiaram o roteiro das entrevistas e as análises.

As entrevistas, focadas nos sujeitos-chave do caso, foram gravadas e transcritas. Entrevistaram-se onze dos treze atores sócios do Grupo Galpão e dois funcionários do Galpão Cine Horto. As entrevistas foram semiestruturadas, pois o roteiro foi composto por poucas perguntas abertas, que permitiram ao respondente certa liberdade para falar e, ao mesmo tempo, guiaram o depoimento por meio de tópicos de interesse (BRYMAN, 1992). Buscou-se intereferir o menos possível na escolha das palavras, temas e personagens que compuseram os depoimentos.

O material coletado foi analisado por meio de elementos da análise do discurso (AD), entre novembro de 2009 a março de 2010. A AD configura-se como uma importante ferramenta para se extrair do discurso a formação ideológica que o permeia e as racionalidades que se relacionam a ela. Neste trabalho, foram utilizados diversos elementos da $\mathrm{AD}$, com vistas a guiar análises mais aprofundadas do significado do processo de produção artística. Segundo Maingueneau (2000, p.13), a análise do discurso é a "disciplina que, em vez de proceder a uma análise linguística do texto em si ou a uma análise sociológica ou psicológica de seu 'contexto', visa a articular sua enunciação sobre um certo lugar social". Um tema caro à análise do discurso é a relação sujeito (enunciador) e estrutura (formação discursiva) (FIORIN, 2003; FARIA, 2001; FOUCAULT, 2007). É importante estabelecer os espaços de atuação do indivíduo, assim como os limites delineados pelas estruturas sociolinguísticas.

Para operacionalizar os preceitos da AD, Faria e Linhares (1993) propõem a identificação de determinadas estratégias discursivas com o intuito de compreender as tentativas do enunciador de persuadir o enunciatário. Tais estratégias estão presentes, explícita ou implicitamente, em todo discurso e se articulam entre os níveis intra e interdiscursivos. Elas podem ser selecionadas conscientemente, de forma calculada para determinados enunciatários, ou podem ser empregadas de forma quase automática. Faria e Linhares (1993) destacam quatro principais estratégias que se manifestam nos enunciados: a criação de personagens, a relação entre temas explícitos e implícitos, o silenciamento e a seleção do vocabulário. Cabe ressaltar, ademais, que no processo de enunciação também 
podem ser empregadas outras estratégias que visam à persuasão, como a forma de apresentação gráfica do discurso e o meio de sua veiculação.

Aliada à identificação das estratégias de persuasão, esta pesquisa buscou analisar o discurso em seu nível individualizado de produção, por meio da análise sintática, da organização intradiscursiva dos enunciados e da possibilidade de determinações do indivíduo no processo de enunciação. Por outro lado, buscou-se também analisar a articulação entre os enunciados individuais nas relações interdiscursivas, levando em consideração a estrutura sociolinguística e os gêneros discursivos (BAKHTIN, 1992; FAIRCLOUGH, 2003). Considerando-se o nível interdiscursivo, buscou-se traçar os principais pontos de contradição entre os diversos enunciados. Faria (2001) denomina tais pontos de divergência como os elementos subjacentes do discurso, que estabeleceriam a relação de contraposição ideológica. Entende-se que o cerne semântico de tais elementos subjacentes aponta para a racionalidade que orienta a prática (discursiva) do enunciador.

Ao longo da exposição das análises, utilizou-se a reprodução de trechos originais das falas dos entrevistados, com vistas a conferir maior transparência aos processos interpretativos realizados. Apesar de o processo analítico encaminhar a certas conclusões, reconhece-se a existência da pluralidade de sentidos passíveis de ser construídos a partir dos relatos. As interpretações que se seguem a partir das análises fazem parte dos sentidos construídos dialogicamente pelos autores, os quais foram refratados por suas subjetividades e visões de mundo (BAKHTIN, 1992). Os trechos reproduzidos são sempre identificados pelos seus enunciadores, cujos nomes foram mantidos em sigilo. Os onze entrevistados do Grupo Galpão estão representados pela sigla GG e seus respectivos números. Vocábulos e expressões mais significantes foram destacados em negrito nos trechos.

\section{ARTISTA FAZ A ARTE E A ARTE 0 ARTISTA: PERCURSOS SEMÂNTICOS SOBRE A ARTE}

As entrevistas coletadas abarcaram uma grande variedade de temas, que puderam ser agrupados em dois grandes percursos semânticos, ou seja, conjuntos mais amplos de sentidos: o "trabalho" e a "arte". Ambos abordam o tema da produção artística, sendo-lhes atrelados, contudo, significados diferenciados. No primeiro, são construídos sentidos acerca da busca de profissionalização, reconhecimento e sobrevivência. No segundo, são tratados temas mais abstratos, ligados ao próprio entendimento do sentido da arte e do fazer artístico para os artistas e para a sociedade. A seguir, as análises se apresentam subdividas pelos percursos semânticos e seus principais temas.

\section{O trabalho e a busca pela profissionalização}

O primeiro grande tema a ser destacado dentro do percurso semântico do trabalho é o da profissionalização. A profissionalização sinaliza o momento em que a identidade de artista se legitima perante a sociedade, envolvendo o reconhecimento externo de sua vocação. O tema da profissionalização surge quando o sujeito assume abertamente seu desejo pela carreira artística, renunciando a outros tipos de trajetórias.

\begin{abstract}
Na Esposa muda [A comédia da esposa muda, peça do Grupo Galpão, 1986], que foi um divisor de águas, mesmo. Que aí eu resolvi assumir mesmo a coisa de atuar e de ficar por conta do Galpão e tal. [...] eu já tava muito em crise com a escola, também, sabe? Achando que não ia dar certo eu virar engenheiro, já tava com essa... E, assim quando você fica buscando alguma coisa pra escapar da outra, assim, né? Então, também chegou na hora e foi difícil mais com o povo em casa, pros pais e tal. (GG11)
\end{abstract}

\begin{abstract}
Quando eu falei que queria ser artista foi uma tristeza.. tristeza. Ela [a mãe] passou por uma grande decepção, da filha ser... ficou muito decepcionada comigo, e quando eu larguei a universidade então [...] Mas, eu não conseguia, não conseguia, eu queria viajar, fazia tudo de graça, mas eu queria era um caminho, um rabinho do balão no ar sacudindo. O balão pra eu ir, senão eu ia ficar insatisfeita, era uma questão mesmo de saber o que eu queria, eu sabia. (GG2)
\end{abstract}

\footnotetext{
Aí eu tirei, eu tirei licença na faculdade e comecei a pedir contagem de tempo no Estado, até sair. Mas ainda demorei um pouco pra sair. [...] E daí pra frente eu já comecei a me dedicar mais ainda, porque antes eu não tinha tempo pra isso. (GG8)
}

O início da profissionalização é geralmente relatado pelos entrevistados como um momento determinado em sua vida, em que eles abriram mão de alternativas profissionais para focar o trabalho com o teatro, buscando a inserção nos sistemas de carreiras enquanto "trabalhadores criativos" (MATTA; SOUZA, 2009, p. 30). 
A decisão é representada como uma escolha pessoal dos enunciadores. Influências externas são silenciadas. Destaca-se, assim, o uso de verbos na primeira pessoa do singular, no pretérito perfeito, como "resolver" e "decidir". Contudo, mais do que o subtema da decisão, os sujeitos entrevistados enfatizam as práticas que foram empreendidas por eles a partir de tal decisão. A ênfase maior dada às práticas pode ter sua razão inferida a partir da ideia de que a maioria dos entrevistados já tinha consciência de sua vocação, sendo a decisão representada como um caminho natural. Essa ideia encontra-se explícita, por exemplo, no trecho dos enunciadores GG11 e GG2.

A primeira prática a ser destacada, relacionada ao início da profissionalização, é a comunicação da decisão para os outros, em geral familiares. Esse seria um movimento de afirmação da racionalidade substantiva, pois o sujeito assume uma posição que lhe parece coerente com seus valores e que vai de encontro à suavização das relações sociais e aos papéis que lhes são impostos. Tal prática está explicitada pelas expressões verbais: "assumir", "falar" e "tirar licença". As personagens discursivas explícitas que representam os receptores da ação de comunicação são os pais e o local de trabalho (faculdade e Estado). Entretanto, pode-se inferir que a sociedade de forma geral seria uma personagem receptora implícita, pois a decisão em iniciar um caminho profissional no teatro acarretaria uma mudança no padrão das práticas sociais dos sujeitos entrevistados.

A prática da racionalidade substantiva requer, muitas vezes, que o indivíduo rejeite as determinações externas que o pressionam para a instrumentalidade (RAMOS, 1981). Nesse sentido, é esperado que tal prática envolva momentos difíceis, o que é corroborado pelas trajetórias individuais aqui analisadas. Os entrevistados recorrem ao tema da decepção, principalmente, por parte da personagem pais. Além da decepção, também é possível inferir que a opção pela carreira de artista acarretou aos entrevistados a situação de dependência financeira. Esse tema fica explicíto frequentemente nos relatos, como, por exemplo, na expressão "fazer tudo de graça" (GG2).

\section{Táticas de sobrevivência}

O tema da dependência financeira encontra-se geralmente relacionado ao tema da sobrevivência. Os entrevistados relatam as várias táticas desenvolvidas, principalmente no início da carreira, para viabilizar a manutenção da prática artística.

\begin{abstract}
Aí, eu falei com ele assim: "Eu não sei como é que eu vou arrumar meu tempo, mas eu vou fazer". Aí eu já comecei a trabalhar. Às vezes o ensaio tava quente e eu tinha que sair porque tinha que dar uma aula. Eu saía mesmo azul de preguiça e de raiva e de tudo [risos]. (GG8)
\end{abstract}

\begin{abstract}
Aí que eu comecei a voltar para o teatro de grupo. Eu passei um ano e pouco caçando grana. E aí, eu já achei grana para uma temporada em São Paulo, que também foi assim um grande fiasco e eu fiquei completamente falido... Assim, voltei de São Paulo com zero de dinheiro. Aí, fui trabalhar numa loja de roupa lá na Savassi [região nobre de Belo Horizonte]. (GG10)

Eu trabalhei como secretária, fazia meio horário. [...] Fazia artesanato, fazia bolsa, trabalhava com couro. Fiz roupa de couro com uma menina, uma bailarina do Palácio das Artes. Fazia roupa pra Patachou. Então, assim, eu me virava assim, sabe? E, como fui entrar em produções que geravam dinheiro de bilheteria, e tal. Então eu já vivia. (GG6)
\end{abstract}

Nesses trechos, o tema do trabalho aparece representado como táticas - práticas oportunistas, empreendidas pelos indivíduos como forma de sobrevivência ou de benefício próprio em um espaço de relações de dominação (CERTEAU, 1994). As táticas transparecem no discurso em várias expressões verbais flexionadas na primeira pessoa do singular, o que indica que são ações praticadas e vislumbradas pelos próprios enunciadores: "dar aula", "trabalhar" e "fazer". A partir de tais expressões, é possível identificar um conjunto de personagens discursivas, muitas vezes implícitas: alunos, patrões e clientes. As táticas dos enunciadores são orientadas em relação às exigências dessas personagens, numa relação muitas vezes de dominação. Contudo, mais do que a relação particular entre cada enunciador e as personagens, destaca-se como tema implícito o próprio sistema social vigente, em que o indivíduo se vê pressionado a realizar trabalhos que não o autorrealizam simplesmente pela sobrevivência.

Nos trechos destacados, observa-se que as táticas de sobrevivência seriam situacionais, como papéis desempenhados instrumentalmente para sustentar a vida de artista teatral. A instrumentalidade está implícita nos trechos, quando os enunciadores vinculam suas táticas exclusivamente ao objetivo de ganhar dinheiro e de sobreviver. Destacam-se, assim, as expressões: 
caçar grana, se virar, gerar dinheiro. Ademais, inferese que a racionalidade praticada a partir das táticas possui sentido secundário para os enunciadores. Por exemplo, GG8 explicita o desejo de não ter que sair do ensaio para dar aula e GG10 explicita que procurava ganhar dinheiro para participar de temporadas de apresentações.

Adicionalmente, GG6 caracteriza a própria prática teatral como forma de sobrevivência financeira. No trecho destacado, pressupõe-se a separação de dois tipos de produções teatrais, aquelas que geram dinheiro e aquelas que não. Nesse sentido, até mesmo certas práticas ligadas ao fazer artístico teatral podem ser representadas como instrumentais, como táticas de sobrevivência. Isso demonstra como pode ser tênue a diferenciação entre sentidos substanciais e instrumentais. Práticas aparentemente semelhantes para o observador externo podem ser orientadas por diferentes racionalidades, adquirindo sentidos específicos para cada sujeito.

A relação entre o trabalho teatral e a sobrevivência, em alguns depoimentos, aparece atrelada ao tema da profissionalização. A representação discursiva do artista profissional seria aquele indivíduo capaz de sobreviver unicamente pela arte.

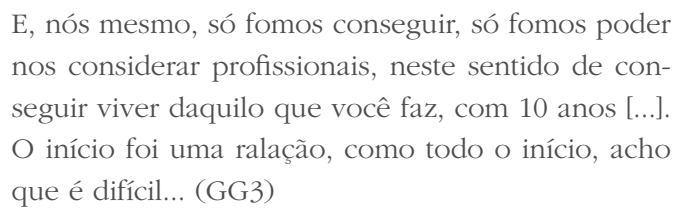
nos considerar profissionais, neste sentido de conseguir viver daquilo que você faz, com 10 anos [...]. O início foi uma ralação, como todo o início, acho que é difícil... (GG3)

O Galpão é minha vida. Acho que é minha profissão há dezenove anos, que eu estou lá. Então, é minha profissão, é meu trabalho, com o Galpão eu consegui criar a minha família. (GG5)

Os dois trechos destacados reproduzem a ideia da profissão como fonte de sustentação financeira. A identidade de profissional do teatro é explicitamente condicionada ao momento em que o indivíduo passa a se manter somente com suas atividades de ator. Nesse sentido, o tema da profissionalização aparece ligado diretamente ao tema do trabalho, agora representado enquanto prática ou vivência na atividade teatral. Prática essa explícita nos termos destacados nos trechos: "ralação" e "trabalho".

\section{Sentidos do fazer teatral}

Ainda considerando os temas do trabalho e da sobrevivência, outros enunciadores revelaram sentidos diferen- tes ao relacioná-los, como no caso de GG7, que coloca explicitamente a identificação com a proposta teatral como condição primeira para atuar ou não.

\footnotetext{
No momento, não tenho a menor vontade de estar fazendo. Não é uma coisa que me... Com esse tempo enorme de vida artística, estou conseguindo não precisar fazer uma coisa que eu não gostaria de estar fazendo. (GG7)
}

É possível notar que, nos textos coletados, a figura discursiva "teatro" recebe dupla representação, sendo relacionada a dois tipos de racionalidade. Enquanto profissão, conforme já exposto, o teatro é visto como ocupação e como meio de sobrevivência, garantindo a existência no mundo. Dessa forma, a prática teatral se relaciona diretamente ao percurso semântico do trabalho e à racionalidade instrumental. Contudo, outros sentidos atribuídos ao teatro, relacionados a um ideal ético ou estético, apontam para a orientação segundo a racionalidade substantiva, indo além do significado do trabalho. Nessa perspectiva, o teatro se apresenta atrelado ao percurso semântico da arte. A figura "teatro", portanto, encontra-se no limiar entre dois percursos semânticos, o que demonstra a rica gama de sentidos que lhe são atrelados.

\section{A arte e os ideais estéticos}

Entendendo-se aqui a arte como atividade de transcendência do homem, como a busca do belo, bom e verdadeiro (TUGENDHAT, 2002), o percurso semântico da arte se descola naturalmente do percurso semântico do trabalho. Apesar de, na vida prática dos sujeitos pesquisados, os sentidos de arte e trabalho se confundirem, é possível destacar momentos em que os enunciadores atrelam o exercício da arte a seus ideais éticos e estéticos. O percurso semântico da arte recebeu atenção específica nesta análise, pois o discurso dos próprios artistas é determinante na definição da arte na sociedade contemporânea. Dessa forma, artista e arte se definem reciprocamente. A análise, portanto, visou compreender a série de sentidos implícita nessa relação.

O primeiro tema a ser analisado se refere aos ideais estéticos dos enunciadores. Ao falarem de suas práticas como artistas, os sujeitos entrevistados revelam suas preferências a respeito da forma que eles fazem arte. O ideal estético, nesse sentido, não remete necessariamente à aparência final do produto da atividade artística, mas sim à busca do processo de fazer arte considerado verdadeiro, realizador e transcendente. 
Só fazer teatro pra ganhar dinheiro não é isso, meu interesse é artístico também, desvendar coisas, desvendar coisas dentro de mim, descobrir coisas e descobrir do outro. O outro me trazer coisas. Eu gosto dessa troca, e sempre trabalhei em grupo, nunca trabalhei de elenco. [...] gosto de trabalhar em grupo. (GG2)

A gente não construiu a Associação Galpão pra ficar rico com o teatro. Isso seria uma ilusão muito grande, mas tem sempre esse sentido artístico dali, do grupo, né, que é decidido sempre... (GG4)

Eu estava cheia de angústia, com vontade de fazer coisas, aprender outras coisas, mas, sendo uma atriz sozinha, convidada pra outros trabalhos, que estímulos eu vou ter, sabe? É difícil... Onde que eu vou desaguar isso tudo que eu estou querendo? (GG6)

Eu quis ser cantor, compositor. Eu comecei a estudar instrumento, mas me faltou disciplina. Aí, o teatro foi abraçando. [...] Tinha alguma coisa a ver com performance, com palco. Tenho fascínio pela mentira, fascínio pela grande verdade. (GG7)

Ao revelar a forma como eles preferem fazer arte, os enunciadores demonstram acreditar em algum tipo de ação criativa, como se essa ação fosse mais autêntica ou verdadeira do que outras. A crença explícita em uma forma de processo artístico, como caminho para se chegar à essência, seja da arte teatral, seja da própria identidade autêntica do artista, conduz a sentidos implícitos sobre a existência de um ideal estético por parte dos enunciadores. Ideal esse que eleva o significado da prática teatral além da esfera existencial e instrumental do trabalho. GG2 e GG4 explicitam, por exemplo, a elevação do fazer teatral acima do objetivo de "ganhar dinheiro" e "ficar rico".

Ainda sobre as preferências artísticas, destacam-se as formas ideais dos enunciadores: teatro de grupo (GG2, GG4, GG6) e o próprio teatro em comparação a outras artes (GG7). Independentemente da forma preferida, contudo, os enunciadores relatam momentos de autoconhecimento ao realizar a arte segundo seus ideais. Esse sentido encontra-se implícito nas expressões: "desvendar coisas dentro de si", "desaguar" e "ter fascínio". Tais expressões remeteriam a um processo de transcendência, de contemplação, em que os sujeitos se aproximariam de suas verdades, por meio de uma racionalidade substantiva. O fazer artístico, nesse ponto, transcende seu resultado, a obra de arte em si, para ganhar sentido subjetivo, enquanto um processo único vivenciado pelo artista.

\section{A arte e os ideais éticos}

Além da busca do ideal estético, alguns enunciadores revelam também um sentido ético implícito na prática artística. A arte, como forma de agir no mundo, assumiria algum tipo de função transcendental, despertadora, educadora, entre outras. Enquanto o tema do ideal estético se relaciona mais com o processo e com a forma do fazer artístico, o tema do ideal ético estaria mais ligado ao produto da arte e aos resultados que ela poderia gerar na sociedade.

Antes de tudo, eu acho que a arte tem uma função social, a priori. [...] A pessoa, se assiste a alguma coisa, já tá abrindo a cabeça dela, tá adquirindo conhecimento, ela tá adquirindo valores civilizatórios. (GG11)

Eu faço teatro, porque é a maneira que eu encontrei de me colocar no mundo. Isso é um ato político [...] Se tem uma resposta, ela deve gerar uma outra pergunta e não aceitar ela, e nesse ponto de vista a gente é político. Eu gosto de espetáculos que, quando você assiste, você leva um pouco pra casa. (GG10)

Eu acho que a única possibilidade da gente conseguir modificar um pouco o caminho que as coisas estão tomando é através da arte, da cultura e da educação. Então, nesse sentido, se um grupo pode promover, ele pode criar alguma esperança, fazer com que as pessoas enxerguem uma possibilidade de uma vida melhor. Eu acho que isso é maravilhoso. (GG6)

Eu acho que é uma maneira de aguçar a sensibilidade das pessoas, da imaginação, o poder da imaginação. Fazer com que as pessoas sonhem. Saiam desse mundo pequeno do dia a dia. Acho que a arte tem muito a ver com isso. (GG9)

Os trechos destacados trazem sentidos implícitos de avaliação sobre o que os enunciadores acreditam ser bom ou desejável para os receptores da arte. Trata-se, portanto, de expressões de julgamento baseadas em conjuntos de valores, que podem revelar significados éticos relacionados ao produto da prática artística. Tais significados conferem sentido ao fazer artístico, sendo a arte representada como forma de transformar o mundo. Assim, o tema da transformação se relaciona diretamente ao tema do ideal ético. Ao agir guiado pela ética, o indivíduo transcende a esfera instrumental da existência para buscar uma participação ativa no mundo, vislumbrando modificá-lo em prol de um vir-a-ser diferenciado (MANNHEIN, 1986). Nos trechos destaca- 
dos, a arte é representada como forma de provocar a mudança nos espectadores. Isso fica explícito nas várias expressões verbais que caracterizam a prática artística: "abrir a cabeça", "adquirir conhecimento", "levar um pouco pra casa", "modificar", "criar esperança", "aguçar a sensibilidade", "fazer sonhar".

Ao representar a arte enquanto forma de agir no mundo, contudo, os enunciadores diferem em relação a sua função transformadora, revelando sentidos diversos sobre o ideal ético a ser buscado pela prática artística. GG11 reproduz o discurso da cultura afirmativa, ou seja, da arte como instrumento pedagógico a serviço da afirmação da cultura (MARCUSE, 2001). Infere-se que a situação ideal para o enunciador seria que os "valores civilizatórios" fossem igualmente acessíveis a todos. Nesse ponto, questiona-se a própria existência de ideal ético no discurso, entendendo-se que o sentido atribuído à arte está menos relacionado à transformação do que à suavização do funcionamento da sociedade. GG11 deixa implícita a ideia de que importa menos o conteúdo intrínseco desses valores do que sua função de aculturamento ou inclusão social. O sentido, portanto, distancia-se de um ideal ético e aproxima-se da moralidade funcional.

GG10, por outro lado, relaciona a prática artística a um posicionamento político. A arte não seria uma forma de homogeneização de valores, mas sim um instrumento para gerar provocação e questionamentos na vida dos espectadores. O ideal ético do enunciador seria alcançado por meio da arte ao causar polêmica e levar à revisão das condições existenciais de quem a aprecia. Dessa forma, o objetivo do enunciador ao fazer arte seria de transformar os espectadores em sua vida cotidiana.

GG6 e GG9 representam a arte como instrumento lúdico. Contudo, por um lado, GG6 explicita que a arte deveria estimular os espectadores a crer num futuro melhor, transformando permanentemente o mundo, "O caminho que as coisas estão tomando". Por outro lado, GG9 representa a arte como uma forma de elevar momentaneamente os espectadores além da esfera cotidiana. Para este último, a função da arte seria transcendente, porém transitória, ideia implícita em "sair desse mundo pequeno do dia a dia".

\section{A prática ética além do fazer artístico}

Embora a maioria dos entrevistados relacione a prática artística a certo tipo de ação em prol de um ideal ético, alguns sujeitos negam o potencial de transformação que a arte em si possa resultar no mundo.

\begin{abstract}
Eu acho que o teatro complementa. Eu acho que não é muito não. Eu acho que é pouco, só se apresentar. É pouco, a troca social. Você vai lá, a pessoa assiste, viaja, acha bonito, distrai um pouco das coisas da realidade, porque ela vê a realidade aumentada ou diminuída ali... Eu acho que é uma questão importante. Mas a prática social mesmo, o teatro não consegue dar. (GG2)
\end{abstract}

Essa é uma discussão que eu tento pôr fogo nela desde muito tempo: quão importantes são as atividades além do espetáculo para a sobrevivência dos grupos, quão importantes são as atividades, enfim, para criar uma sociedade melhor. (GG1)

Os trechos destacados trazem implícita a ideia de que a arte por si só não transforma o mundo. Caberia ao artista atuar de outras formas para modificar a realidade. Nesse sentido, os temas do ideal ético e da transformação ainda se encontram presentes não na prática artística, mas sim na prática do artista enquanto sujeito ativo no mundo. Esses enunciadores, portanto, constroem a ideia de um ideal ético que deve ser buscado além de suas identidades enquanto artistas. O compromisso dos enunciadores com a mudança social está explícito nas expressões "prática social" e "criar uma sociedade melhor".

O percurso semântico da arte revela momentos em que os enunciadores exercitam práticas racionalmente substantivas, pois a busca de ideais extracotidianos e extraexistenciais levaria os sujeitos a uma prática além da esfera instrumental. Dessa forma, eles visariam modificar o mundo e/ou serem continuamente modificados, num processo de autoconhecimento e de reafirmação identitária. Por outro lado, o percurso semântico do trabalho revela indivíduos que possuem trajetórias únicas e que acabam tendo que desenvolver táticas de sobrevivência e práticas instrumentais, com vistas a sustentar a prática artística autêntica.

\section{CONSIDERAÇÕES FINAIS}

Na pesquisa em questão, notou-se que o Grupo Galpão era composto por indivíduos que, de alguma forma, estavam interessados em produzir arte coletivamente. Tal interesse poderia ser pautado pela racionalidade instrumental ou substantiva. A racionalidade que predomina nas práticas do grupo pode se impor à ação individual, mas também o sujeito poderia atuar taticamente construindo bricolagens em prol do exercício de uma racionalidade autêntica, ressignificando sua participação no grupo. 
Apesar da separação dicotômica entre racionalidades instrumentais e substantivas, para efeito de análise, observa-se que a prática dessas racionalidades no cotidiano dos artistas ocorre de forma híbrida, sendo difícil traçar limites entre elas. Em algumas situações, parecem estar envolvidos objetivos instrumentais e substantivos, variando-se num continuum entre a importância conferida a cada um deles. No caso dos artistas analisados, nota-se que a racionalidade substantiva, baseada na identificação com a arte e seus ideais estéticos e/ou éticos, possui influência considerável nas decisões da vida deles, muitas vezes fazendo-os abrir mão de reconhecimento social e familiar, ganhos financeiros e de grandes bilheterias, por exemplo.

A análise, portanto, revelou sujeitos que se orientam pela racionalidade substancial, baseada na busca de uma prática autêntica enquanto artistas. A carreira artística teria sido reconhecida como vocação ou gosto pela arte. A filiação dos indivíduos ao Grupo Galpão seria motivada por sentidos substanciais, com diferentes dosagens de instrumentalidade. Tais dosagens poderiam variar segundo a identificação do sujeito com ideais éticos e estéticos contidos na prática coletiva, de um lado, e segundo a busca de manutenção da existência a partir da prática artística enquanto tática de sobrevivência, de outro.

A partir das análises do material empírico, é possível propor que os indivíduos empreendem suas práticas diárias a partir de dosagens de racionalidades diferentes, podendo em cada momento ser uma mais predominante que a outra. Sujeitos e agrupamentos se diferenciam em suas trajetórias a partir da racionalidade, que ganha maior relevância em suas práticas cotidianas. Dessa forma, constroem-se identidades (individuais e coletivas) distintas.

A grande maioria dos entrevistados vislumbrou a estratégia identitária da profissionalização artística e do trabalho em grupo como forma de conciliar racionalidades em sua prática cotidiana. Enquanto profissionais, eles garantiriam o reconhecimento externo e a sobrevivência. Enquanto atores de grupo, eles viveriam processos criativos com maior liberdade e com interações pessoais autênticas. Nesse sentido, no interior do Grupo Galpão, como em qualquer organização de produção artística, seria preciso conciliar espaços de transcendência criativa e espaços de sobrevivência econômica. Ademais, faz-se necessária a conciliação mínima de ideais éticos e/ou estéticos entre os membros, para que a produção conjunta de arte ocorra; e de práticas organizacionais, para que a interação com o mercado também aconteça.
O presente artigo buscou evidenciar as contradições intrínsecas à prática da arte na contemporaneidade, considerando as pressões da indústria cultural e o sentido transcendente da arte. A questão que se faz neste momento seria a respeito da possibilidade de manutenção do equilíbrio de racionalidades na produção artística. Tendo que se submeter às exigências mercadológicas, a busca de ideais éticos ou estéticos continuaria sendo uma questão autêntica ou se esvaziaria de sentido diante da instrumentalidade? É verdadeiramente possível conciliar esses ideais, calcados na busca da transcendência humana, com a conformação ao sistema de compra e venda de bens culturais, cujo poder de decisãose encontra na mão de organizações econômicas? Caminhos táticos de subversão a esse sistema seriam mais éticos ou estéticos e, assim, mais autenticamente artísticos?

Espera-se que as conclusões e, principalmente, os questionamentos levantados possam contribuir para preencher lacunas no campo de estudos sobre indústrias culturais. Organizações que atuam na produção artística se deparaam frequentemente com dilemas relacionados à coexistência de racionalidades diferentes nos padrões das relações interpessoais. Acredita-se que a contribuição deste estudo de caso do Grupo Galpão foi lançar luz sobre esse tema, demonstrando caminhos teóricos que podem ser explorados. Destaca-se a inexistência de estudos sobre o fazer artístico com referencial teórico semelhante ao utilizado nesta pesquisa. Nesse sentido, este estudo pode ser considerado relevante para que se ampliem zonas de sentido a respeito das práticas em outras organizações semelhantes (REY, 2005). Além disso, acredita-se que se contribuiu para a área porque se apontaram caminhos metodológicos relacionados ao desvendamento de sentidos subjacentes às práticas discursivas dos sujeitos. Tais sentidos, revelados pela análise do discurso, podem assinalar as racionalidades que orientam o fazer artístico em situações diversas. Finalmente, contudo, as conclusões desta pesquisa são limitadas pela incapacidade de se apreender integralmente a subjetividade dos sujeitos envolvidos para que as racionalidades sejam totalmente desnudadas.

Pesquisas futuras são sempre bem-vindas, com vistas à expansão das zonas de sentido aqui propostas. Acredita-se ser interessante a análise da identidade coletiva de artistas agrupados em sistemas sociais diferenciados, mais ou menos inseridos no mercado de bens culturais. Propõe-se também aprofundar estudos em outros tipos de grupos, fora da esfera 
artística, com práticas de naturezas diferentes, para que sejam comparadas as racionalidades e as identidades construídas.

\section{REFERÊNCIAS}

ARENDT, H. A condição bumana. Rio de Janeiro: Forense Universitária, 2004.

AVELAR, R. O avesso da cena: notas sobre produção e gestão cultural. Belo Horizonte: DUO Editorial, 2008.

BAKHTIN, M. Estética da criação verbal. São Paulo: Martins Fontes Editora, 1992.

BENDASSOLLI, P. F; WOOD JR, T. KIRSCHBAUM, C; CUNHA, M. P. Indústrias criativas: definição, limites e possibilidades. RAE-revista de administração de empresas, v. 49, n. 1, p. 1018, 2009.

BENDASSOLLI, P. F; WOOD JR, T. O paradoxo de Mozart: carreiras nas indústrias criativas. Revista OES, v. 17, n. 53, p. 259-277, 2010.

BENJAMIN, W. A obra de arte na era de sua reprodutibilidade técnica (1936). In: BENJAMIN, W. Magia e técnica, arte e política: ensaios sobre literatura e história da cultura. São Paulo: Brasiliense, 1994.

BENJAMIN, W. Passages, magasins de nouveautés, calicots. In: BENJAMIN, W. Passagens. Belo Horizonte: Editora UFMG; São Paulo: Imprensa Oficial do Estado de São Paulo, 2007.

BOEIRA, S. L; MUDREY, D. Teoria da delimitação de sistemas sociais em duas unidades da Uni-Yôga. Revista OES, v. 17, n. 52, p. $157-173,2010$.

BRANDÃO, C. A. L. Grupo Galpão: uma história de risco e rito. Belo Horizonte: O Grupo, 2002.

BRYMAN, A. Research Methods and Organization Studies. London: Unwin Hyman, 1992.

CERTEAU, M. de. A invenção do cotidiano: artes de fazer. Petrópolis, RJ: Vozes, 1994.

DEFILLIPPI, R; GRABHER, G; JONES, C. Introduction to paradoxes of creativity: managerial and organizacional challenges in the cultural economy. Journal of Organizational Behavior, v. 28, n. 5, p. 511-521, 2007.
DUARTE, R. A indústria cultural global e sua crítica. In: DUARTE, R; FIGUEIREDO, V; FREITAS, V; KANGUSSU, I. (Orgs) Kátharsis: reflexos de um conceito estético. Belo Horizonte: Editora C/Arte, 2002. p. 251-264.

FAIRCLOUGH, N. Analysing Discourse: textual analysis for social research. Londres: Routledge, 2003.

FARIA, A. A. M. Interdiscurso e intradiscurso: da teoria à metodologia. In: MENDES, E. A. de M.; OLIVEIRA, P. M.; BENN-IBLER, V. (Orgs) O novo milênio: interfaces linguísticas e literárias. Belo Horizonte: FALE/UFMG, 2001. p. 31-37.

FARIA, A. A. M., LINHARES, P. T. S. O preço da passagem no discurso de uma empresa de ônibus. In: MACHADO, I. L. (Org) Análises de discursos: sedução e persuasão. Cadernos de Pesquisa do NAPq. Belo Horizonte: FALE/ UFMG/NAPq, no $13,1993$.

FIORIN, J. L. Linguagem e ideologia. São Paulo: Ática, 2003.

FOUCAULT, M. A arqueologia do saber. Rio de Janeiro: Forense Universitária, 2007.

GALLEN, C; BOUDER-PALLER, D. Comprendre les freins à la consommation de spectacles vivants à travers la conception individuelle de l'art. Décisions Marketing, n. 58, avril-juin, 2010.

GLYNN, M. A. When cymbals become symbols: conflict over organizational identity within a symphony orchestra. Organization Science, v. 11, n. 3, Special Issue, p. 285298, 2000.

HORKHEIMER, M; ADORNO, T. A indústria cultural - o iluminismo como mistificação das massas (1947). In: ALMEIDA, J. M. B. (Org) Indústria cultural e sociedade: Theodor Adorno. São Paulo: Paz e Terra, 2007.

LAMPEL, J; LANT, T; SHAMSIE, J. Equilíbrio em cena: o que aprender com as práticas organizacionais das indústrias culturais. RAE-revista de administração de empresas, v. 49, n. 1, p. 19-26, 2009.

MAINGUENEAU, D. Termos-chave da análise do discurso. Belo Horizonte: Editora UFMG, 2000.

MANNHEIM, K. Ideologia e utopia. Rio de Janeiro: 1986.

MARCUSE, H. A ideologia da sociedade industrial. Rio de Janeiro: Zahar, 1973. 
MARCUSE, H. Sobre o caráter afirmativo da Cultura (1937). In: MARCUSE, H. Cultura e psicanálise. São Paulo: Paz e Terra, 2001, p. 89-136

MATTA, J. P. R; SOUZA, E. R. L. C. 'Cidade de Deus' e 'Janela da alma' um estudo sobre a cadeia produtiva do cinema brasileiro. RAE-revista de administração de empresas, v. 49, n. 1, p. 27-37, 2009.

OLIVEIRA, R. P; VIEIRA, M. M. F; ROSIMERI, C. S. O sentido da arte: o caso do Centro Cultural Banco do Brasil - RJ. Revista Organizações \& Sociedade, v. 14, n. 43, p. 129-140, 2007.

RAMOS, A. G. A nova ciência das organizações: uma reconstrução da riqueza das nações. Rio de Janeiro: Editora da FGV, 1981.

REY, F. G. Pesquisa qualitativa e subjetividade: os processos de construção da informação. São Paulo: Pioneira Thomson Learning, 2005.

SOARES, M. Resistência e revolução no teatro: arena conta movimentos libertários (1965-67). 2002. 119 p. Dissertação de Mestrado em História da Universidade Federal de Uberlândia, Uberlândia, 2002.

SOUZA, M. M. P; SANTOS, A. P. Repensando a identidade nas organizações: por uma visão integrativa de práticas, discursos e racionalidades. In: ENCONTRO DE ESTUDOS ORGANIZACIONAIS DA ANPAD, 6, 2010, Florianópolis. Anais eletrônicos. Florianópolis: ANPAD, 2010.

TUGENDHAT, E. Nietzsche e o problema da transcendência imanente.Ethic@, v. 1, n. 1, p. 47-62, 2002.

VIZEU, F. Ações comunicativas e estudos organizacionais. $R A E-$ revista de administração de empresas, v. 45, n. 4, p. 10-21, 2005.

WEBER, M. Economia e sociedade: fundamentos da sociologia compreensiva (1901). São Paulo: Imprensa Oficial do Estado de São Paulo, 2004.

YIN, R. K. Estudo de caso: planejamento e métodos. Porto Alegre: Bookman, 2001 